\title{
Preparation and characterization of magnesium-aluminium-silicate glass ceramics
}

\author{
MADHUMITA GOSWAMI, T MIRZA, A SARKAR, SHOBHA MANIKANDAN, SANGEETA, \\ S L VERMA, K R GURUMURTHY ${ }^{\dagger}$, V K SHRIKHANDE and G P KOTHIYAL* \\ Technical Physics and Prototype Engineering Division, ${ }^{\dagger}$ Atomic Fuel Division, Bhabha Atomic Research Centre, \\ Mumbai 400 085, India
}

MS received 28 June 2000

\begin{abstract}
Synthesis of machinable quality magnesium aluminium silicate $\left(\mathrm{MgO}-\mathrm{Al}_{2} \mathrm{O}_{3}-\mathrm{SiO}_{2}\right)$ for fabrication of insulators/spacers usable in high voltage applications under high vacuum conditions has been carried out following two different routes i.e. (i) sintering route, and (ii) glass route. A three-stage heating schedule involving calcination, nucleation and crystallization, has been evolved for the preparation of magnesium aluminium silicate (MAS) glass ceramic with $\mathrm{MgF}_{2}$ as a nucleating agent. The effect of sintering temperature on the density of compacted material was studied. Microstructure and machinability of samples obtained from both routes were investigated. They were also characterized for microhardness. Initial studies on material obtained by glass route reveal that these samples are superior to those obtained from sintered route in respect of their high voltage breakdown strength and outgassing behaviour. Outgassing rate of $10^{-9}$ Torr $1 \cdot \mathrm{s}^{-1} \mathrm{~cm}^{-2}$ and breakdown strength of $160 \mathrm{kV} / \mathrm{cm}$ were obtained. Different types of spacers, lugs, nuts and bolts have been prepared by direct machining of the indigenously developed glass ceramic.
\end{abstract}

Keywords. Machinable glass ceramic; magnesium aluminium silicate.

\section{Introduction}

Glass ceramics based on $\mathrm{MgO}-\mathrm{Al}_{2} \mathrm{O}_{3}-\mathrm{SiO}_{2}$ (MAS) system, are technologically important materials for various applications involving high voltage and ultra high vacuum. They have not only unique feature of machinability, but also have superior electrical insulation, ultra-high vacuum compatibility, high thermal stability, low thermal conductivity and good mechanical strength (Grossman 1972; Taira and Yamaki 1979; Baik et al 1995; Boccaccini 1997; Pannhorst 1997; Kothiyal et al 1999; Xu and Jahanmir 1999). Various properties of MAS glass ceramics such as hardness, machinability, conductivity etc, among other parameters depend on the composition and microstructure. These glass ceramics can be machined to precise tolerances and surface finish with conventional metal working tools. In fact, the good machinability feature of MAS is due to unique microstructure of interlocking array of plate like mica crystals, dispersed uniformly throughout glassy matrix. The components fabricated using these glass ceramics have also been found suitable for aerospace and nuclear industry. These glass ceramic materials are prepared by controlled crystallization in which, a large number of tiny crystals rather than few bigger single crystals are grown

\footnotetext{
*Author for correspondence
}

(McMillan 1964; Zdaniewski 1973). Radonjic and Nikolic (1991) studied the effect of the fluorine content and its source on the crystallization of this class of material. They identified predominant crystalline phases as fluorite, norbergite or fluorophlogopite depending on heat treatment, fluorine concentration etc. General methods of preparation have been discussed in the literature (Beall 1971; Grossman 1972; Beall and Doman 1980), but because of the special category of this technologically important material, the crucial process has either been kept vague or missing. Therefore, the development of these materials assumes special importance for meeting indigenous requirements. Some work has been carried out in our laboratory on the preparation of machinable quality glass ceramic with and without the use of commercial mica (Kulkarni et al 1990; Dalvi et al 1991). However, the work on the preparation of machinable MAS glass ceramic using constituent oxides was recently undertaken.

In this paper we report the preparation of magnesium aluminium silicate glass ceramic using oxides/carbonates of $\mathrm{Si}, \mathrm{Mg}, \mathrm{Al}, \mathrm{B}$, and $\mathrm{K}$ as base charge and $\mathrm{MgF}_{2}$ as nucleating agent, following two different routes i.e. controlled crystallization through surface nucleation (sintering route) and bulk nucleation (glass route). Nucleation and crystallization temperatures were broadly determined by DTA. The effects of heat treatment on porosity and density of compacted samples were studied. The microstructure of both types of samples was seen through 
SEM, while their machinability was evaluated using conventional lathe machine. Further, suitability of the material for ultra high vacuum and high voltage applications was assessed by measuring their outgassing rates and electrical breakdown voltage, respectively. Outgassing rate as low as $10^{-9}$ Torr $1 \cdot \mathrm{s}^{-1} \mathrm{~cm}^{-2}$ and high voltage breakdown strength of $\sim 160 \mathrm{kV} / \mathrm{cm}$ were obtained.

\section{Experimental}

MAS glass ceramic samples were prepared following sintering as well as glass routes using three-stage schedules involving calcination, nucleation and crystallization processes. For sintering route, the general procedure followed was similar to that reported earlier (Kulkarni et al 1990; Dalvi et al 1991). In both cases, the initial charge was prepared by taking AR grade chemicals in approximate weight percentage of $\mathrm{SiO}_{2} 45-50 ; \mathrm{Al}_{2} \mathrm{O}_{3}$ 15-18; $\mathrm{MgO} 17-20 ; \mathrm{K}_{2} \mathrm{O} 8-10$ and $\mathrm{B}_{2} \mathrm{O}_{3}$ 6-10. In the first stage, the initial charge was mixed thoroughly and calcined at $950^{\circ} \mathrm{C}$ for $24 \mathrm{~h}$ with a pre-determined heating schedule. Approximately 4-7 wt $\% \mathrm{MgF}_{2}$ was added to the calcined charge and was pulverized in a planetary ball mill (PM 4000 model Retsh, Germany), for $40 \mathrm{~h}$ in an alumina jar. The particle size of the ball-milled sample was around $10 \mu \mathrm{m}$ as measured on Malvern 6/10 Easy particle sizer. Further processing of the charge was done differently for sintering route and glass (monolithic) route.

\subsection{Sintering route}

In this case, finely ball milled charge was seasoned in $5 \%$ $\mathrm{H}_{3} \mathrm{PO}_{4}$ acid solution in acetone medium for a period up to $72 \mathrm{~h}$. Compacts of various sizes (maximum $50 \mathrm{~mm}$ dia. and $25 \mathrm{~mm} \mathrm{ht}$ ) were prepared in a hydraulic press using $\sim 200 \mathrm{~kg} / \mathrm{cm}^{2}$ pressure. They were then sintered using a two-step heating programme. In the first step, the compact was heated up to $\sim 600$ to $630^{\circ} \mathrm{C}$ for $2-4$ h to ensure good nucleation and to initiate crystal growth. In the second step, heating was carried out with different heating rates in the range of $15-60^{\circ} \mathrm{C} / \mathrm{h}$ up to crystallization/ sintering temperatures of $950-1070^{\circ} \mathrm{C}$. The sample was maintained at the sintering temperature for a sufficiently long time to achieve the desired crystal growth. Samples were crystallized/sintered at different temperatures mentioned above. In order to see the effect of higher sintering temperature on the density, a separate experiment was carried out by heating the individual sample $(25 \mathrm{~mm}$ dia. $\times 10 \mathrm{~mm} \mathrm{ht}$ ) to different temperatures, in the range $1060-1175^{\circ} \mathrm{C}$, at the rate of $60^{\circ} \mathrm{C} / \mathrm{h}$ and holding there for $2 \mathrm{~h}$ before cooling to room temperature. DTA measurement was carried out on TG-DTA system model $92 \cdot 18$ of $\mathrm{M} / \mathrm{s}$ Setaram, France. About 20-25 mg of powder sample was taken in a $100 \mu \mathrm{l} \mathrm{Pt}$ crucible. The chamber was initially pumped to $10^{-3}$ Torr and then flushed by Ar gas, for about $15 \mathrm{~min}$, before starting the experiment. Sample was heated up to $1050^{\circ} \mathrm{C}$ at the rate of $10^{\circ} \mathrm{C} / \mathrm{min}$ in $\mathrm{O}_{2}$ atmosphere using alumina as reference.

\subsection{Glass route}

The calcined and ball milled charge, prepared as mentioned earlier, was melted in a covered platinum-rhodium (Pt-Rh) crucible for $2-4 \mathrm{~h}$ at about $1450-1550^{\circ} \mathrm{C}$ temperature in the lowering and raising hearth furnace (model 'OKAY' 70R10, M/s Bysakh and Co., Calcutta) and the melt was poured into graphite/brass moulds. Glass disc/cylinder of maximum size (about $40 \mathrm{~mm}$ dia. and $25-30 \mathrm{~mm} \mathrm{ht}$ ) was obtained. This was immediately transferred to an annealing furnace maintained at around $550-575^{\circ} \mathrm{C}$. After annealing, the furnace was cooled to room temperature at the rate of $20^{\circ} \mathrm{C} / \mathrm{h}$. In order to transform this glass to glass ceramic, controlled nucleation and crystallization were carried out in a programmable vertical tubular furnace using different heating schedules. For nucleation, the temperature of the sample was kept at about $600-630^{\circ} \mathrm{C}$ for $4-6 \mathrm{~h}$ and was raised to 1000 $1050^{\circ} \mathrm{C}$ for crystallization, based on the experience with sintering process and DTA data (discussed later). After crystallization, the sample was cooled to room temperature at the pre-determined rate. Samples were prepared by using different crystallization temperatures and for varying periods of 4-6 h. In addition, studies were also carried out using different heating rates; varying from $15-60^{\circ} \mathrm{C} / \mathrm{h}$ from nucleation to crystallization stage.

The open porosity of the sample was measured by boiling the sample in distilled water at $100^{\circ} \mathrm{C}$ for $2 \mathrm{~h}$. Bulk density of the sample was measured at room temperature by the liquid displacement method using distilled water (Archimedes method). The surface finish of sample was measured on a profilometer (Taylor Hobson Surtronic-3 model) by LVDT method. For this purpose, the sample was first machined on a conventional lathe (maximat) using different carbide tipped tools and then polished with $0.3 \mu \mathrm{Al}_{2} \mathrm{O}_{3}$ powder for $1 \mathrm{~h}$ before measurement. Chemical analysis of the base glass and glass ceramic samples, prepared by both methods, was done by standard analytical techniques. Crystallization and phase formation were monitored by XRD (model Rigaku D4000, Japan), while scanning electron microscopy (SEM) was employed for studying the microstructure. For SEM measurements, gold coating was given by vacuum evaporation/deposition on HF etched naturally fractured surface. The measurements were done on SEM model: Stereoscan S-240, Cambridge, UK.

The high voltage breakdown strength was measured by the conventional two-electrode method. The electrodes were made of brass having about $25 \mathrm{~mm}$ dia. tips. The sample was prepared in the form of a disc, with a cavity having a radius of curvature of $12.5 \mathrm{~mm}$, formed on each 


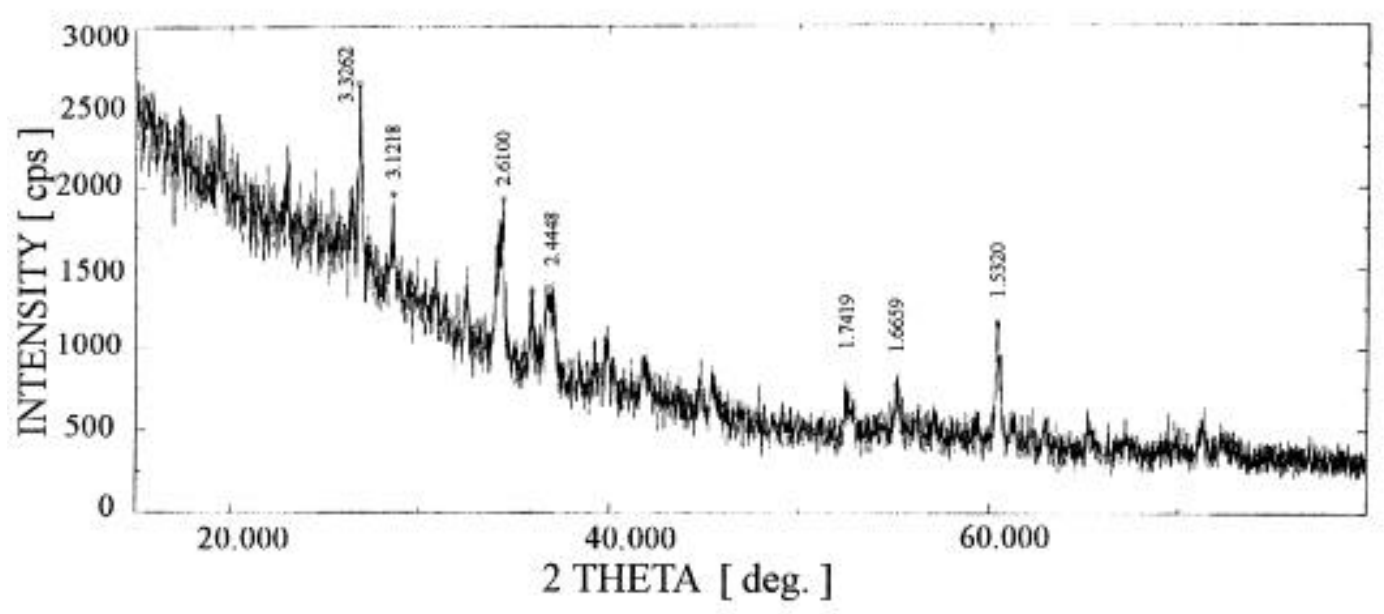

Figure 1. XRD pattern for MAS glass ceramic prepared by sintering route.

side by machining such that the thickness at the centre was reduced to $1.5-2.0 \mathrm{~mm}$. The sample was held between two electrodes and immersed in an oil bath. The voltage was slowly raised until the breakdown occurred.

The microhardness of the sample was measured by indentation technique using Vickers diamond pyramid indentor on the microhardness tester (model VMHT $30 \mathrm{M}$, Leica). Before measurements, the sample surface was polished with $0 \cdot 3 \mu$ alumina powder to get good reflective surface. The measurement was done on the polished surface by applying $300 \mathrm{~g}$ load for $10 \mathrm{sec}$. An average of at least 10 readings was taken. Outgassing rate was measured using a special UHV setup enabling the sample to be heated up to $400^{\circ} \mathrm{C}$. A sample of about $20 \mathrm{~mm}$ dia was used for this measurement. The system was maintained at $10^{-9}$ Torr vacuum before starting the experiments.

\section{Results and discussion}

\subsection{Sintering route}

A solid cylinder of maximum $50 \mathrm{~mm}$ dia $\times 25 \mathrm{~mm} \mathrm{ht}$ was obtained with existing dies. It was observed that if the initial charge was not pulverized for a sufficiently long time after calcination, the sintered block had lot of open pores on the surface. In some cases even laminations were also seen. Charge after $35-40 \mathrm{~h}$ ball milling gave $80 \%$ of particles having $<10 \mu \mathrm{m}$ and remaining particles having 10-20 $\mu \mathrm{m}$ size. The smaller and uniform particle size distribution and sintering temperature of $1050^{\circ} \mathrm{C}$ produced the material of high density $(2.44 \mathrm{~g} / \mathrm{cc})$ and zero porosity. Figure 1 shows the XRD pattern for such a glass ceramic sample. The well formed diffraction patterns and ' $d$ ' values confirm that the predominant phase formed is fluorophlogopite. The surface roughness of this sample was found to vary from 0.7 to $0.9 \mu \mathrm{m}$

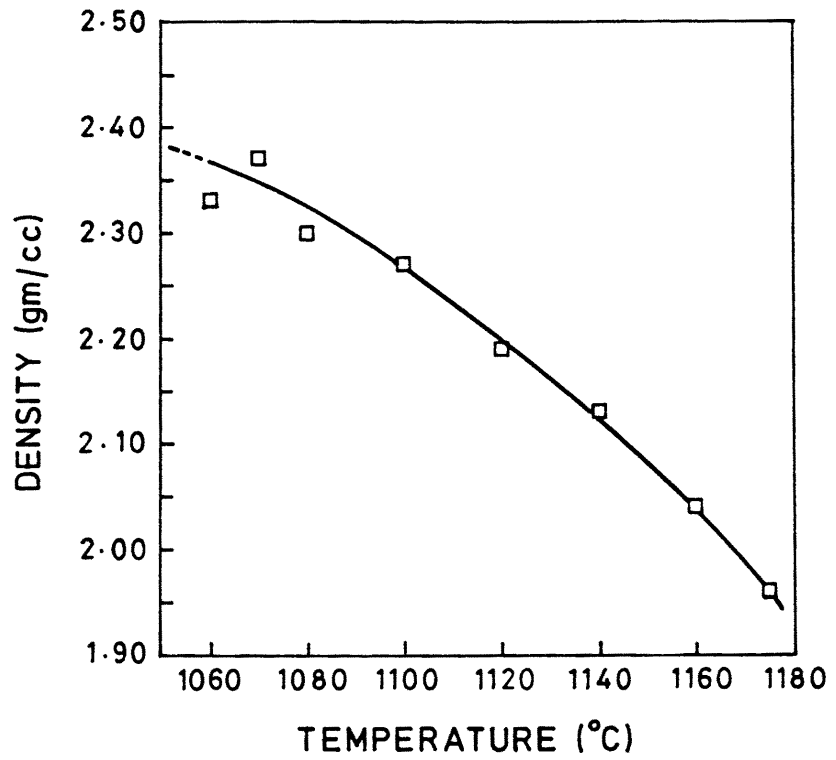

Figure 2. Variation of density with sintering temperature for MAS glass ceramic prepared by sintering route.

indicating a very good quality of the material. Chemical analysis of these samples did not show any significant deviation from the starting charge composition.

The results of heat treatment on the density of sintered material as a function of sintering temperature are shown in figure 2. A monotonous decrease in density is observed with higher sintering temperatures. As the sintering temperature is increased beyond $1060^{\circ} \mathrm{C}$, enhanced thermal energy leads to some reordering/rearrangement among the grains as well as some anisotropic crystal growth. In addition, decomposition of fluorophlogopite phase, formed at the lower temperature, takes place leading to the development of internal line cracks/voids (Radonjic and Nikolic 1991) in the material. As a result of this, the material seems to swell and its density decreases at higher sintering temperatures. It is our observation that 
the density is rather insensitive to the rate of heating for crystallization but the sintering temperature has a definitive effect on it. It can be inferred from this result that sintering temperatures $>1060^{\circ} \mathrm{C}$ are not desirable for processing MAS.

The microstructure of a good sample, shown in SEM photograph, is reproduced in figure 3. The photograph shows the presence of interlocking, planar platelike microstructure with average crystallite size of about $20 \mu \mathrm{m}$ which is responsible for machinability of this material.

Outgassing rates for as prepared sintered samples, at room temperature, are found to be $1.8 \times 10^{-7}$ Torr $1 \cdot \mathrm{s}^{-1} \mathrm{~cm}^{-2}$. After heating to $400^{\circ} \mathrm{C}$ for $3 \mathrm{~h}$, the rate increased to $8 \times 10^{-6}$ Torr $1 \cdot \mathrm{s}^{-1} \mathrm{~cm}^{-2}$. The sample after cooling to room temperature attained the outgassing rate of nearly $10^{-9}$ Torr $1 \cdot \mathrm{s}^{-1} \mathrm{~cm}^{-2}$ indicating its suitability for use in UHV systems being used up to a vacuum of $10^{-9}$ Torr. Table 1 shows some measured physical parameters of the developed material.

\subsection{Glass route}

The maximum size of the sample obtained by pouring the melt into brass/graphite moulds was about $40 \mathrm{~mm}$ dia $\times 25 \mathrm{~mm}$ thick. This size is presently limited by the availability of $\mathrm{Pt}-\mathrm{Rh}$ crucible with us. In order to transform this glass into glass ceramic, it was essential to determine the nucleation and crystallization temperatures.The DTA curve of this glass sample is shown in figure 4a. This curve compares well with the one obtained for glass ceramic prepared by sintering process, as shown in figure $4 \mathrm{~b}$. Both show exothermic peaks in the range $540-625^{\circ} \mathrm{C}$ and several peaks in the range $700-1030^{\circ} \mathrm{C}$. The tempera-

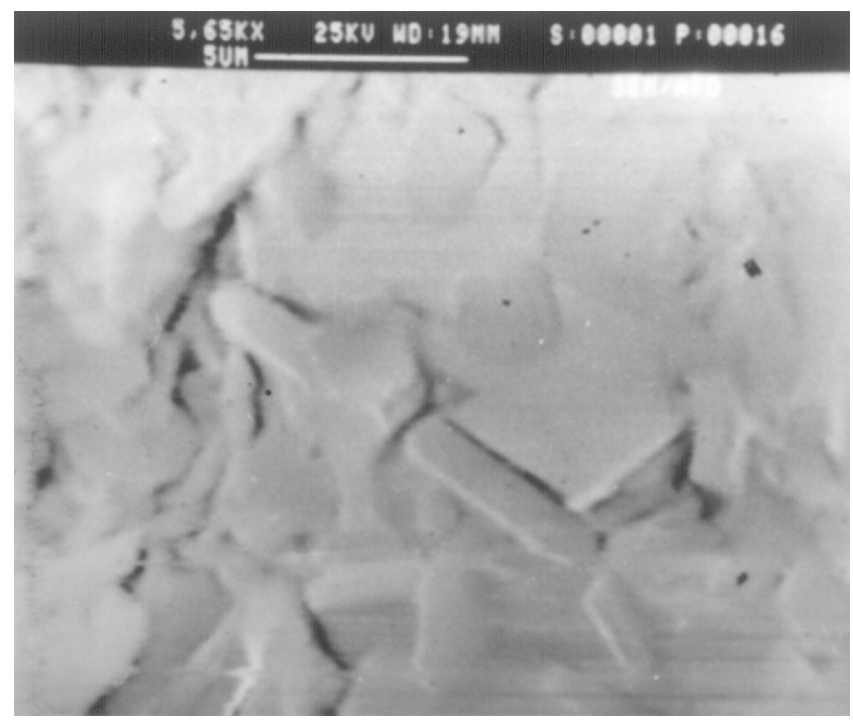

Figure 3. SEM photograph of MAS glass ceramic prepared by sintering route. ture range of $540-625^{\circ} \mathrm{C}$ is thus related to the nucleation (phenomenon) process and the exothermic peaks between $700-1030^{\circ} \mathrm{C}$ to crystallization of various phases. Based on these data, the nucleation and crystallization studies were carried out on glass samples. The results of initial studies on heating rates and maximum growth temperatures pointed out that the temperature of nucleation around $600^{\circ} \mathrm{C}$ and the crystallization temperature around $1050^{\circ} \mathrm{C}$ alongwith lower heating rates of $15-20^{\circ} \mathrm{C} / \mathrm{h}$ were

Table 1. Density, microhardness and breakdown strength of glass ceramic samples prepared by sintering and glass routes.

\begin{tabular}{lccc}
\hline Sample & $\begin{array}{c}\text { Density } \\
(\mathrm{g} / \mathrm{cc})\end{array}$ & $\begin{array}{c}\text { Microhardness } \\
\left(\mathrm{kg} / \mathrm{mm}^{2}\right)\end{array}$ & $\begin{array}{c}\text { Breakdown } \\
\text { strength } \\
(\mathrm{kV} / \mathrm{cm})\end{array}$ \\
\hline Sintering route & 2.44 & 466.5 & 110 \\
Glass route & 2.61 & 425.8 & 160 \\
(Base glass) & $(2.55)$ & $(612.8)$ & - \\
\hline
\end{tabular}
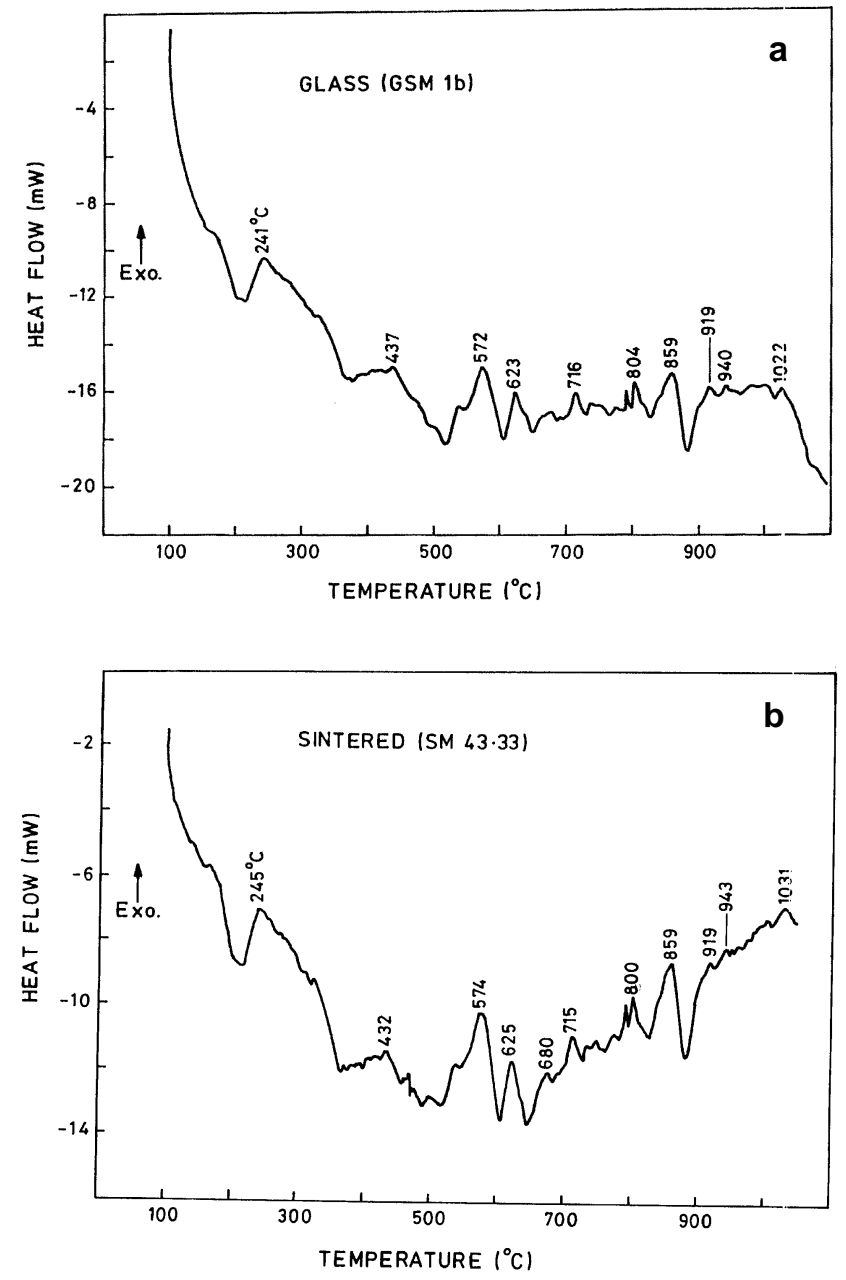

Figure 4. a. DTA curve for base glass used for preparing MAS glass ceramic prepared by glass route and b. DTA curve for MAS glass ceramic prepared by sintering route. 


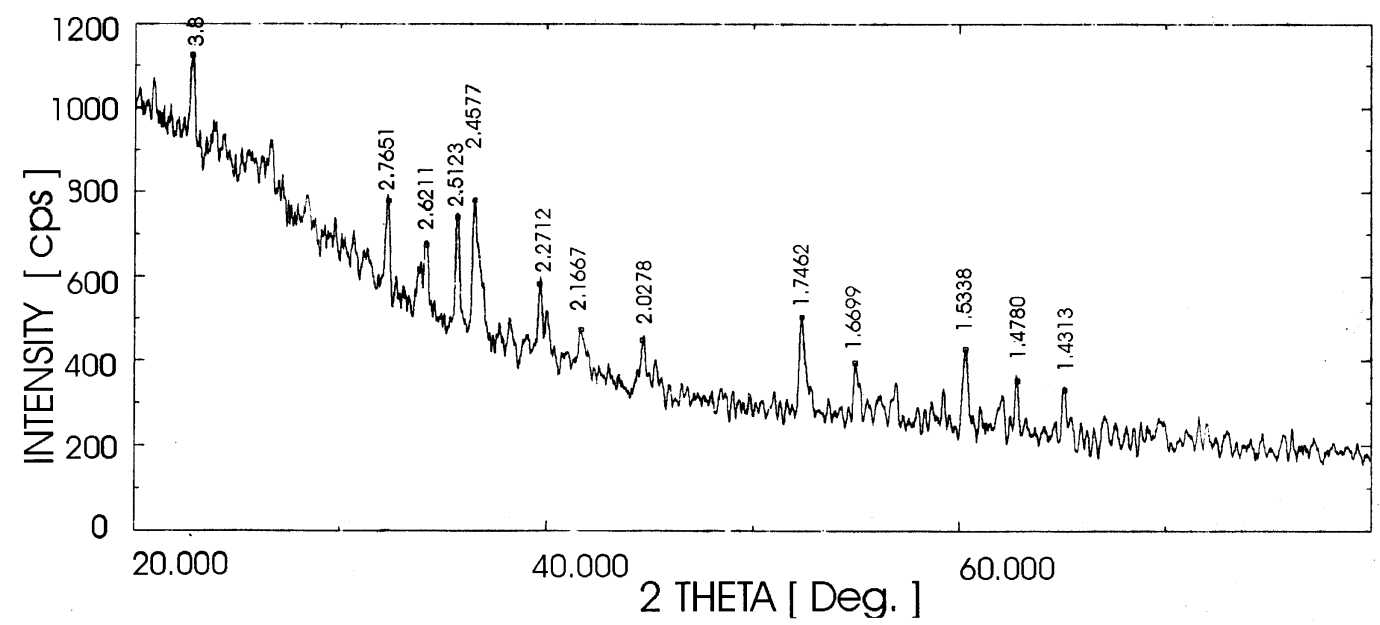

Figure 5. XRD pattern for MAS glass ceramic prepared by glass route.

conducive for the development of desired microstructure. The samples obtained after annealing showed very smooth surface with practically zero porosity as expected.

Figure 5 shows the XRD pattern of glass ceramic. Various diffraction peaks have been indexed. The predominant phase in this material has been identified as magnesium fluorosilicate (chondrodite) along with the presence of other phases like norbergite and magnesium silicate. Formation of norbergite phase is attributed to the deficiency of fluorine in the base glass (Radonjic and Nikolic 1991).

SEM of monolithic sample revealed the interlocking chainlike microstructure (figure 6). Outgassing rates, for as prepared monolithic samples, at room temperature are found to be $7.8 \times 10^{-8}$ Torr $1 \cdot \mathrm{s}^{-1} \mathrm{~cm}^{-2}$, which is lower than that prepared by sintering process. Lower outgassing rate is obviously due to zero porosity of these samples. After heating to $400^{\circ} \mathrm{C}$ for $3 \mathrm{~h}$, the rate was about an order of magnitude lower. Finally, the outgassing rate reduced to nearly $10^{-9}$ Torr $1 \cdot \mathrm{s}^{-1} \mathrm{~cm}^{-2}$ at room temperature, which is roughly the same as seen for sintered sample. Since our set up was capable of giving vacuum of $10^{-9}$ Torr only, the exact quantitative value of outgassing rate could not be ascertained.

The density, microhardness and breakdown voltage are given in table 1 . The lower value of breakdown strength and density, in the case of sintered sample, may be due to presence of closed pores arising during compaction. Lower value of microhardness for glass ceramic sample prepared by glass route suggests better machinability.

Machinability of samples was tested by changing various parameters i.e. cutting speed, cutting angle, spindle speed etc. A spindle speed of $54 \mathrm{sfm}$ with carbide tipped tool having a cutting angle of $5^{\circ}$ is found to give the best surface finish in the present samples. Both types of materials were found to have good machinability. This is due to microstructure of interlocking array of plate and chain like crystallites, dispersed uniformly to the glassy matrix.

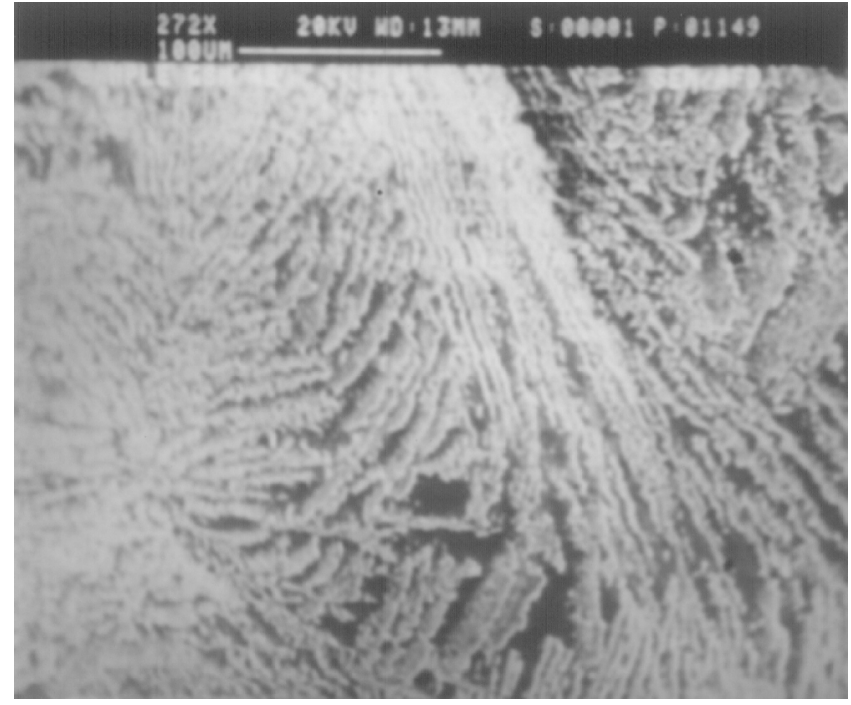

Figure 6. SEM photograph of MAS glass ceramic prepared by glass route.

A number of special types of spacers, lugs, insulators, nuts and bolts have been prepared, at present, using the material from sintered route, for use in UHV systems and high voltage applications (figure 7). Their performance has been found to be satisfactory. The material from glass route is expected to give superior properties.

\section{Conclusion}

We have obtained machinable quality magnesium aluminium silicate glass ceramics by two processes (i.e. sintering and glass routes). Initial results on the material produced by glass route are found to give better surface finish, less porosity, higher density and electrical break- 


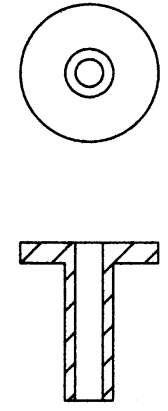

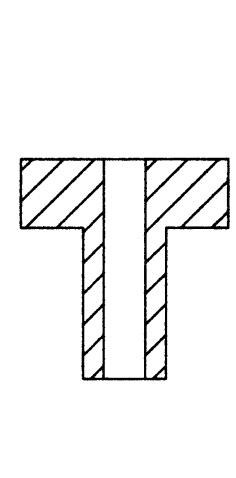
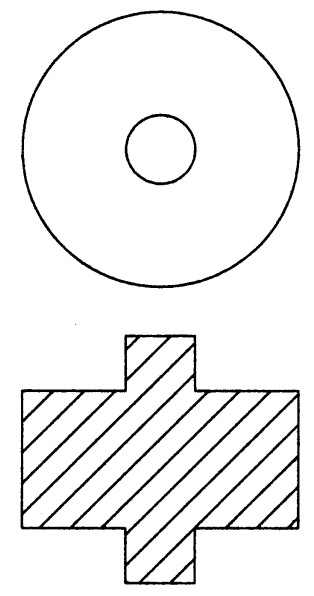

(c)
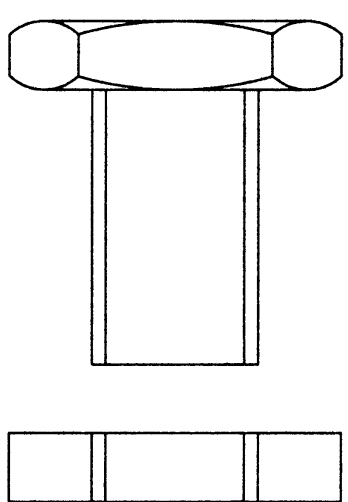

(d)

Figure 7. Typical HV lugs/insulators prepared from MAS glass ceramic by sintering route. (a) and (b) current lead supports for UHV system, (c) spacers for sputter ion pump and (d) general purpose nut and bolt.

down strength compared to those prepared by sintered method. However, both types of samples show suitability for UHV and high voltage applications. More detailed studies are needed to be done on the samples prepared by glass route to exploit their superior properties.

\section{Acknowledgements}

The authors wish to thank Dr V C Sahni, Head, TP\&PED, for his constant support and encouragement. We sincerely acknowledge the fruitful discussions with Shri Ram Prasad, MPD, in the initial stages of work pertaining to sintering route. They would like to thank Dr S C Sabharwal, TP\&PED, for providing DTA and XRD facilities; Shri W C J Carvalho, TP\&PED, for making outgassing setup available, Shri A K Sinha, L\&P TD, for help in high voltage breakdown measurements. Our special thanks are due to Dr Padmanabhan, L\&P TD, for help in initial charge preparation, Dr S S Thantry, ACD, for chemical analysis, Shri R Kameshwaran, ACD, for particle size analysis, Shri Ahmed, AFD, for surface finish measurement and to Shri J K Panchal, TP\&PED, for machining glass ceramics and preparing some special purpose insulators, lugs etc. The valuable technical assistance received from S/Shri B B Sawant, P A Wagh and B B Pandare is gratefully acknowledged.

\section{References}

Baik D S, No K S, Chun J S, Yoon Y Y and Cho H Y 1995 J. Mater. Sci. 301801

Beall G H 1971 Structure properties and application of glass ceramics, Symp. on nucleation and crystallization in glasses (eds) L L Hench and S W Frieman (Columbus, Ohio: Amer. Ceram. Soc.) p. 250

Beall G H and Doman R C 1980 Sci. Ceram. 1025

Boccaccini A R 1997 J. Mater. Process. Technol. 65302

Dalvi P Y, Bagyatkar P, Kulkarni A K, Mirza T and Halbe S R 1991 Presented at the fiftyfifth annual technical meeting of Indian Ceramic Society, Calcutta

Grossman D G 1972 J. Am. Ceram. Soc. 55 251, 446

Kulkarni A R, Dalvi P Y, Mirza T and Patil B A 1990 Presented at the fiftyfourth annual technical meeting of Indian Ceramic Society, BARC, Mumbai

Kothiyal G P, Sawant B B, Mirza T and Shrikhande V K 1999 Proc. DAE-BRNS National symp. on recent trends in electro and magnetoceramics (ed.) B K Chougule (Kolhapur: Shivaji University) p. 25

McMillan P W 1964 Glass ceramics (London and New York: Academic Press)

Pannhorst W 1997 J. Non-Cryst. Solids 219198

Radonjic Lj and Nikolic Lj 1991 J. Eur. Ceram. Soc. 711

Taira M and Yamaki M 1979 J. Am. Ceram. Soc. 62345

Xu H H K and Jahanmir S 1999 J. Am. Ceram. Soc. 78497

Zdaniewski W 1973 J. Mater. Sci. 8192 